Research Report

\title{
A COMPARATIVE STUDY OF IMPULSIVITY, LETHALITY AND INTENT AMONG PERSONS ATTEMPTING SUICIDE BY SELF-IMMOLATION AND POISONING
}

\author{
Namita Nazeer ${ }^{1}$, Harish M Tharayil ${ }^{2}$, Varsha Vidyadharan ${ }^{3^{*}}$ \\ ${ }^{1}$ Assistant Surgeon, PHC Chirakkara, Kollam \\ ${ }^{2}$ Professor of Psychiatry, Government Medical College, Kozhikode \\ ${ }^{3}$ Assistant Professor in Psychiatry, Government Medical College, Kozhikode \\ * Correspondence: drvarshavinu@gmail.com
}

First submitted on 3/7/2019 Published online: 2/10/2019

\begin{abstract}
Background: Suicide is one of the top ten leading causes of death in the world as well as India. Poisoning is one of the most common modes of attempting suicide. Self-immolation is a devastating form of suicide attempt. Impulsivity has been demonstrated as an important risk factor for suicide. Lethality and intent were found to be interrelated in previous studies. But a comparative study of impulsivity, lethality and intent between self-immolation and poisoning was not found in a literature search.
\end{abstract}

\section{Objectives:}

1. To compare socio-demographic characteristics, impulsivity, intent and lethality in those who attempt suicide by self-immolation and poisoning.

2. To find the intercorrelations between intent, impulsivity and lethality.

Methods: A cross-sectional comparative study was done among persons attempting suicide by selfimmolation $(n=40)$ and poisoning $(n=50)$. Barratt's impulsivity scale, Smith's LSARS (lethality of suicide attempt rating scale) and Beck's suicide intent scale were used to assess impulsivity, lethality and intent, respectively. Percentages, mean, median and range were used to describe the data. Chisquare test, t-test and Pearson correlation were used for statistical analysis.

Results and discussion: There were significant associations between occupation, family income and socioeconomic status and mode of suicide attempt. Lethality was higher in self-immolation. Lethality and intent were significantly intercorrelated in both groups. Impulsivity and lethality were negatively correlated in the self-immolation group.

Conclusion: Self-immolation is a highly lethal method of attempting suicide. Highly lethal suicide attempts have high intent. Greater the impulsivity, less lethal the attempt is likely to be.

Keywords: self-immolation, poisoning, impulsivity, lethality, intent

Please cite this article as: Namita N, Tharayil HM, Vidyadharan V. Comparative study of impulsivity, lethality and intent among persons attempting suicide by self-immolation and poisoning. Kerala Journal of Psychiatry 2019:32(1): 10-16. doi: 10.30834/K IP.32.1.2019.165 


\section{INTRODUCTION}

Suicide is a deliberate act of self-harm resulting in a fatal outcome. Every year close to 800,000 people die by suicide, and many more attempt it. ${ }^{1}$ Different methods of suicide include poisoning, hanging, self-immolation, drowning, cutting, and jumping off heights and many others. It is estimated that for every suicide, there occurs about more than 30 episodes of non-fatal self-harm. Deliberate self-harm attempted suicide or parasuicide is an acute non-fatal act of self-harm carried out deliberately in the form of an acute episode of behaviour by an individual with variable motivation. ${ }^{2}$ According to the National Crime Records Bureau (NCRB), suicide is one of the top 10 causes of death in India. Suicide attempts are ten times the number of suicides in India. ${ }^{3}$

Poisoning was found to be the most common mode of suicides in previous studies. ${ }^{4}$ Selfimmolation is the most devastating forms of suicide attempt because it is highly fatal and kills the individual very quickly. ${ }^{5}$ Lethality is the seriousness of physical consequences or risk to life of the suicide attempter. ${ }^{6}$ Suicide intent is the actual wish to die or the intensity of the patient's wish to terminate life or the sense of purpose inherent in the act. ${ }^{7}$ Lethality often did not correlate with the intent on many occasions. But a high correlation was seen in the study by Nasser et al. ${ }^{6}$ Impulsivity has been defined as a predisposition towards unplanned reactions to internal or external stimuli, without regard to the negative consequences. Impulsive individuals might be more likely to enact a suicidal ideation. ${ }^{8}$

Previous studies have compared sociodemographic factors between selfimmolation and poisoning. ${ }^{5}$ But the three factors-impulsivity, lethality and intent were not studied between these two groups of patients attempting suicide in any of the previous studies. This study was designed to examine risk factors that might distinguish the selection of self-immolation versus poisoning as a means to commit suicide. Impulsivity is accepted as a good endo-phenotype in suicidal behaviour.' A person with high intent and accurate conception about lethality is at the highest risk; low intent and accurate conception will be at the lowest risk, and high intent and inaccurate conception will be at intermediate risk..$^{10}$

\section{OBJECTIVES}

This study aims to compare sociodemographic characteristics, impulsivity, intent and lethality in those who attempt suicide by self-immolation and poisoning and to determine intercorrelations between intent, impulsivity and lethality.

\section{MATERIALS AND METHODS}

\section{Study design}

It was a cross-sectional comparative study. Sample size was calculated by the formula $\mathrm{N}=$ $\left(\mathrm{z}_{\mathrm{a}}+\mathrm{z}_{\mathrm{b}}\right) \times \mathrm{SD}^{2} \times 2 / \mathrm{d}^{2}=50.31$ Where $\mathrm{z}_{\mathrm{a}}=1.96$, $\mathrm{z}_{\mathrm{b}}=0.84, \mathrm{SD}=2.38, \mathrm{~d}=0.63$ (10\% of the mean of a previous study). ${ }^{11}$

\section{Setting and participants}

The study was conducted in the Psychiatry Department of Govt. Medical College, Kozhikode. Consecutive samples were taken from general medicine, surgery and psychiatry wards. Total of 50 patients attempting suicide by poisoning and 40 patients attempting suicide by burns were included in the study. The study period was ten months from January 2017 to October 2017. Institutional Ethics Committee 
clearance was obtained. Subjects aged 14-75 years, who gave informed consent to participate in the study and survived at least 48 hours were included. Patients who survived less than 48 hours, attempted suicide through means other than poisoning or selfimmolation (e.g., hanging, cutting), or had cognitive dysfunction making it difficult to interview were excluded.

\section{Variables and statistical methods}

Assessment tools used were a semi-structured datasheet covering basic socio-demographic details. As there were no validated tools available in local language Malayalam, we translated the tools following the WHO method of forward and backward translation by two independent experts. The following tools were used by us. Barratt's Impulsivity Scale (BIS-II) was used to assess trait impulsivity. ${ }^{12}$ Beck's suicide intent scale was used to assess the intent of suicide. ${ }^{13}$ Lethality of suicide attempt rating scale (LSARS) was used for lethality. ${ }^{14,15}$ These three and the demographic variables were compared between the two groups of suicide attempters, i.e. self- immolation and poisoning. Data analysis was carried out using the Statistical Package for Social Sciences (SPSS) version 18. Chi-square test was used for categorical variables, t-test for quantitative variables and Pearson's correlation were done.

\section{RESULTS}

Ninety patients were studied, of which 50 attempted suicide by poisoning and 40 by self-immolation. In both groups, most of the patients were in the age group of $14-45$ years. Males and females were in equal number in both groups. Most of the persons were married. But these factors were not statistically significantly associated with the mode of attempting suicide. Most of the people who attempted self-immolation were unskilled workers, whereas subjects presented with poisoning had an almost equal number of skilled and unskilled workers. Poisoning group had significantly higher family income. There is a statistically significant association between family income, occupation, socioeconomic status and the mode of suicide attempt in this study (Table 1).

Lethality by self-immolation is significantly higher than poisoning. Lethality score has a mean of 5.91 with a standard deviation of 1.95 in the poisoning group. In self-immolation group mean for lethality score is 7.48 with a standard deviation of 0.85 . Mean impulsivity score in the poisoning group is 69.08 , with a standard deviation of 10.13 . In the selfimmolation group, the mean impulsivity score is 67.23 , with a standard deviation of 8.3. We can see that in both self-immolations and poisoning, impulsivity is higher than the normal range, which is $50-60$ (as measured in healthy controls).$^{11}$ Mean intent score is 26.66 in the poisoning group with a standard deviation of 5.86 while in self-immolation group it is 27.43 with a standard deviation of 8.28. In both self-immolation as well as poisoning group, there is a medium intent in the present study. Lethality is higher in selfimmolation (Table-2). The correlations among impulsivity, intent and lethality are given in table 3 . Lethality and intent are significantly correlated in both groups. Impulsivity and lethality are negatively correlated in the self-immolation group. 
Table 1: Sample characteristics of cases that attempted suicide

\begin{tabular}{|c|c|c|c|c|}
\hline Characteristics & $\begin{array}{c}\text { Poisoning } \\
\text { N (\%) }\end{array}$ & $\begin{array}{c}\text { Self - immolation } \\
\mathrm{N}(\%)\end{array}$ & $\begin{array}{l}\mathrm{X}^{2} / \mathrm{t} \\
(\mathrm{df})\end{array}$ & P-value \\
\hline $\begin{array}{l}\text { Age group (years) } \\
<18 \\
14-45 \\
>45\end{array}$ & $\begin{array}{c}2(4) \\
34(68) \\
14(28)\end{array}$ & $\begin{array}{c}2(5) \\
25(62.5) \\
13(32.5)\end{array}$ & $-1.879(88)$ & 0.064 \\
\hline \begin{tabular}{|l} 
Sex \\
Male \\
Female
\end{tabular} & $\begin{array}{l}28(56) \\
22(44)\end{array}$ & $\begin{array}{l}17(42.5) \\
23(57.5)\end{array}$ & $1.620(1)$ & 0.203 \\
\hline $\begin{array}{l}\text { Marital status } \\
\text { Unmarried } \\
\text { Married } \\
\text { Widow } \\
\text { Separated }\end{array}$ & $\begin{array}{l}20(40) \\
29(58) \\
1(2) \\
0(0)\end{array}$ & $\begin{array}{c}8(20) \\
26(65) \\
4(10) \\
2(5)\end{array}$ & $6.575(3)$ & 0.087 \\
\hline $\begin{array}{l}\text { Socio-economic Status } \\
\text { Low } \\
\text { Middle }\end{array}$ & $\begin{array}{l}40(80) \\
10(20)\end{array}$ & $\begin{array}{c}39(97.5) \\
1(2.5)\end{array}$ & $6.343(1)$ & $0.012^{*}$ \\
\hline $\begin{array}{l}\text { Occupation } \\
\text { Skilled } \\
\text { Semi-skilled } \\
\text { Unskilled }\end{array}$ & $\begin{array}{l}15(30) \\
13(26) \\
22(44)\end{array}$ & $\begin{array}{l}4(10) \\
6(15) \\
30(75)\end{array}$ & $9.180(2)$ & $0.01^{*}$ \\
\hline $\begin{array}{l}\text { Family Income (monthly) } \\
<1000 \\
1000-5000 \\
5000-10000 \\
>10000\end{array}$ & $\begin{array}{c}4(8) \\
6(12) \\
27(54) \\
13(26)\end{array}$ & $\begin{array}{c}4(10) \\
8(20) \\
27(67.5) \\
1(2.5)\end{array}$ & $2.325(88)$ & $0.022^{*}$ \\
\hline
\end{tabular}

$\mathrm{t}=\mathrm{t}$ value on Independent $\mathrm{t}$-test; $\chi 2=$ Pearson Chi-Square value; $\mathrm{df}-$ Degree of freedom; ${ }^{*} \mathrm{P}<0.05$

Table. 2. Comparison of impulsivity, lethality and intent in Poisoning vs Self-immolation

\begin{tabular}{|c|c|c|c|c|c|c|}
\hline Factor & \multicolumn{2}{|c|}{ Poisoning } & \multicolumn{2}{c|}{ Self-immolation } & \multicolumn{2}{|c|}{} \\
\hline & Mean & SD & Mean & SD & Mean difference & p-value \\
\hline Lethality & 5.91 & 1.95 & 7.48 & 0.85 & -1.5650 & $<0.001^{*}$ \\
\hline Impulsivity & 69.08 & 10.13 & 67.23 & 8.3 & 1.855 & 0.353 \\
\hline Intent & 26.66 & 5.86 & 27.43 & 8.28 & -0.765 & 0.610 \\
\hline
\end{tabular}

SD-standard deviation; ${ }^{*} \mathrm{P}<0.05$ 
Table 3: Correlations among impulsivity, intent and lethality in suicides by self-immolation and poisoning

\begin{tabular}{|c|c|c|c|c|}
\hline \multirow{2}{*}{} & \multicolumn{2}{|c|}{ Self Immolation } & \multicolumn{2}{c|}{ Poisoning } \\
\cline { 2 - 5 } & Intent score & Lethality score & Intent score & Lethality score \\
\hline Impulsivity score & & & & \\
Pearson correlation & -0.137 & $-0.428^{*}$ & -0.058 & $0.038^{*}$ \\
Sig. (2 tailed) & 0.398 & 0.006 & 0.689 & 0.795 \\
\hline Intent score & & $0.607^{*}$ & 1 & $0.472^{*}$ \\
Pearson correlation & & $<0.001$ & & 0.001 \\
Sig. (2 tailed) & - & & & \\
\hline
\end{tabular}

$* \mathrm{P}-<0.05$

\section{DISCUSSION}

In the present study, socioeconomic status and occupation were found to be significant factors affecting the mode of suicide attempt. In the study by Kalist et al. in 2007, it was found that suicide attempts and suicidal ideation were negatively related to personal income and the probability of employment. ${ }^{16}$ In a study by Smith et al. in 2014, it was again found that higher incomes are associated with fewer suicide rates. ${ }^{17}$ However, in a study by Saurina et al. in 2013, no clear association between suicide rates and income could be established. ${ }^{18}$

According to previous studies, burns is a highly lethal means of attempt. In a retrospective review article by Castana et al. in 2013, despite the low incidence of suicide attempts by self-immolation, this was associated with much higher mortality. ${ }^{19}$ In the present study, both self-immolations, as well as poisoning, result in high lethality.

Intent and lethality were positively correlated. The present results corroborate previous reports where there was a close relationship between suicide intent and lethality of attempt. In a study by Zhang et al.,2007, it was found that lethality of means of attempt is positively correlated with suicide intent. ${ }^{11}$ In another study by Saptya et al. 2012, it was found that intent and lethality were related to each other for attempts occurring in early adulthood. ${ }^{10}$

In poisoning attempts, there was a positive and significant correlation between intent and lethality scores. This is similar to that of findings of previous studies that lethality of means is positively correlated with the degree of suicide intent. ${ }^{20,21}$. Impulsivity and lethality in the present study were also positively correlated but not significant. There was a negative but non-significant correlation between impulsivity and intent. But this is in accordance with findings of the previous study by Lim et al. in 2016, that impulsive attempts being made in earlier stages of suicide ideation have less intent and less likely to be lethal. ${ }^{22}$

In the self-immolation group, impulsivity and intent score were negatively correlated, but this was not statistically significant. This finding is in accordance with previous studies on suicide, but the correlation between impulsivity and intent in specific cases of 
suicides by self- immolation have not been reported so far. ${ }^{23}$

The present study established a significant negative correlation between impulsivity and lethality scores. This means that greater the impulsivity, the suicide attempt will be less lethal or vice versa. This finding is contrary to the findings of a previous study, in which it was found that those who attempt suicide by burning were highly impulsive. ${ }^{23}$ In a psychological autopsy study by Venkoba Rao et al. in 1989, it was found that suddenness and impulsive nature of attempt characterise burns. ${ }^{24}$ In a study by Kannapiran et al. in 1997 , it was found that self-immolators were impulsive aggressive and sensitive. ${ }^{25}$

The major findings from the present study are that intent and lethality of suicide attempts were positively correlated and significant in suicide attempts by both self-immolation and poisoning. Among the correlations studied, the magnitude of correlation was highest among these two attributes. It establishes that a high intent at suicidal death will ensure lethality as also reported from previous studies. Self-immolation was found to be a highly lethal method of attempting suicide. Highly lethal suicide attempts were associated with high intent. However, greater the impulsivity, less lethal the attempt is likely to be.

Limitations of the study were that the sample size was small. Adequate number of selfimmolation cases were not there for assessment due to low admission rates during the period of study. Barratt's impulsivity scale being a self-rated questionnaire may have resulted in bias while marking responses by the patient.

\section{REFERENCES}

1. World Health Organization. Preventing suicide: a global imperative. World Health Organization. 2014. Available from: http://www.who.int/iris/handle/10665/131056 Last accessed in November 2015.

2. Cowen P, Harrison P, Burns T. Shorter Oxford textbook of psychiatry. 6th ed. Oxford: Oxford University Press.2012;421-440.

3. National Crime Records Bureau. Accidental Deaths and Suicides in India. 2015;192.

4. Menon V, Kattimani S, Sarkar S, Muthuramalingam A. Gender differences among suicide attempters attending a Crisis Intervention Clinic in South India. Ind Psychiatry J. 2015 JanJun;24(1):64-9.

5. Rezaie L, Khazaie H, Soleimani A, Schwebel DC. Is self-immolation a distinct method for suicide? A comparison of Iranian patients attempting suicide by self-immolation and by poisoning. Burns. 2011 Feb;37(1):159-63.

6. Nasser EH and Ovelholser JC. Assessing varying degrees of lethality in depressed adolescent suicide attempters. Acta Psychiatr Scand. 1999; 99:423-31.

7. Hamdi E, Amin Y, Mattar T. Clinical correlates of intent in attempted suicide. Acta Psychiatr Scand. 1991; 83:406-11.

8. Moeller FG, Barratt ES, Dougherty DM, Schmitz JM, Swann AC. Psychiatric aspects of impulsivity. Am J Psychiatry. 2001; 158:1783-93.

9. Mann JJ, Arango, VA, Avenevoli S, Brent, DA, Champagne FA, Clayton, $\mathrm{P}$, et al. Candidate endophenotypes for genetic studies of suicidal behaviour. Biol Psychiatry. 2009;65(7), 556-63.

10. Sapyta J, Goldston D, Erkanli A, Daniel S, Heilbron N, Mayfield A, et al. Evaluating the predictive validity of suicidal intent and medical lethality in youth. Journal of Consulting and Clinical Psychology. 2012; 80:222-231.

11. Zhang Jxu H. Degree of suicide intent and the lethality of means employed: a study of Chinese attempters. Arch Suicide Res. 2007;11(4):343-50. 
12. Moeller FG, Barratt ES, Dougherty DM, Schmitz JM, Swann AC, 2001. Psychiatric aspects of impulsivity. Am J Psychiatry 158, 1783-93.

13. Beck AT, Beck R and Kovacs M. 1975. Classification of suicidal behaviours I. Quantifying Intent and Medical lethality. Am J Psychiatry 132(3): 285-87

14. Smith K, Conroy RW and Ehler BD. Lethality of suicide attempt rating scale. Suicide Life Threat Behav. 1984;14(4): 215-42

15. Nasser EH and Overholser JC. Assessing varying degrees of lethality in depressed adolescent suicide attempters. Acta Psychiatr Scand. 1999; 99(6): 423-431

16. Kalist DE, Molinari NA, Siahaan F. Income, employment and suicidal behaviour. J Ment Health Policy Econ.2007;10(4):177-87.

17. Smith NDL, Kawachi I. State-level social capital and suicide mortality in the 50 US states. Soc Sci Med. 2014; 120:269-77.

18. Saurina C, Bragulat B, Saez M, LopezCasasnovas G. A conditional model for estimating the increase in suicides associated with the 2008-2010 economic recession in England. J Epidemiol Comm Health. 2013; 67:779-87.

19. Castana O, Kourakos P, Moutafidis M, Stampolidis N, Triantafyllou V, Filippa E. et al. Outcomes of patients who commit suicide by burning. Ann Burns Fire Disasters.2013;26(1):36-39.

20. Nock MK, Kessler RC: Prevalence of and risk factors for suicide attempts versus suicide gestures: analysis of the national comorbidity survey. J Abnorm Psychol 2006, 115(3):616-23.

21. Goldston DB, Daniel SS, Erkanli A, Heilbron N, Doyle O, Weller B, et al. Suicide attempts in a longitudinal sample of adolescents followed through adulthood: Evidence of escalation. J Consult Clin Psychol. 2015;83(2):253-64.

22. Lim M, Lee S, Park JI. Differences between Impulsive and Non-Impulsive Suicide Attempts among Individuals Treated in Emergency Rooms of South Korea. Psychiatry Investig. 2016 Jul; 13(4):389-96.

23. Sonneborn CK, Vanstraelen PM. A retrospective study of self-inflicted burns. Gen Hosp Psychiatry1992;14(6):404-7

24. Venkoba Rao A, Mahendran N, Gopalakrishnan C, Reddy TK, Prabhakar ER, Swaminathan R, et al. One hundred female burns cases: A study in suicidology. Indian J Psychiatry.1989; 31(1): 4350.

25. Kannapiran T, Haroon AE, Vivekanandan S, Arnagiri S. Personality profiles of selfimmolators. Indian J Psychiatry.1997;39(1): 3740. 